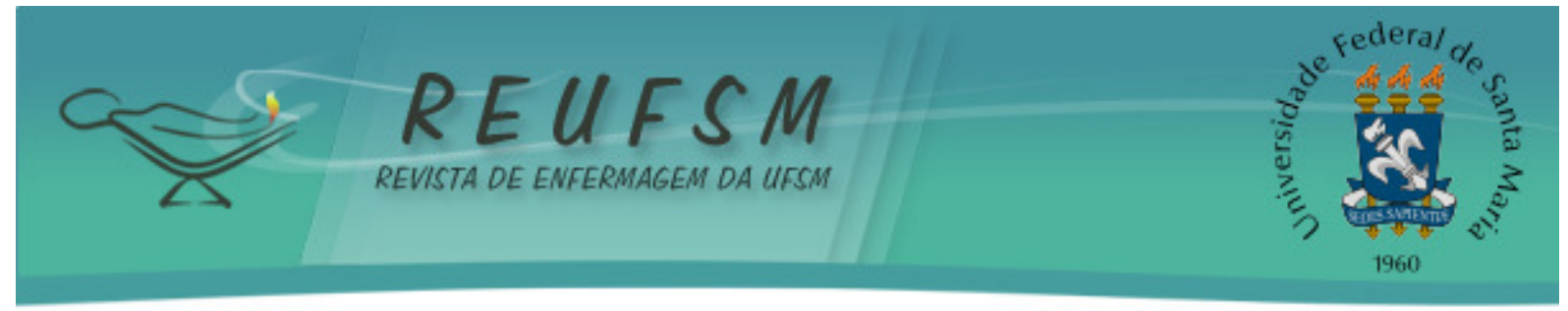

ARTIGO ORIGINAL

\title{
A POLISSEMIA DA HIGIENIZAÇÃO DE MÃOS NO CONTEXTO HOSPITALAR: COM A PALAVRA, OS USUÁRIOS
}

\section{THE POLYSEMY OF HANDS HYGIENE IN THE HOSPITAL CONTEXT: THE USERS' VOICE \\ LA POLISEMIA DE LA HIGIENIZACIÓN DE MANOS EN EL CONTEXTO HOSPITALARIO: CON LA PALABRA, LOS USUARIOS}

\author{
Carem Gorniak Lovatto ${ }^{1}$ \\ Maíra Rosseto ${ }^{2}$ \\ Dora Lucia Leidens Correa de Oliveira ${ }^{3}$
}

\begin{abstract}
Doi: $10.5902 / 2179769221258$
\end{abstract}
RESUMO: Objetivo: analisar os sentidos atribuídos por pessoas internadas em um hospital do sul do Brasil às mensagens veiculadas por cartazes em campanha para a promoção da higienização de mãos. Método: estudo qualitativo exploratório-descritivo. Dados foram coletados por meio de entrevistas com 10 pacientes. Procedeu-se análise temática com base no referencial dos Estudos Culturais. Resultados: foram atribuídos sentidos diversos às mensagens dos cartazes, o que resultou em leituras e respostas distintas à campanha. Como ação, a higienização das mãos foi representada pelos pacientes como uma responsabilidade específica do profissional a fim de evitar infecções. Considerações Finais: os sentidos atribuídos às mensagens pelos pacientes foram diferentes dos esperados pelos produtores da campanha, resultando em respostas não compatíveis com seus objetivos.

Descritores: Educação em saúde; Controle de infecções; Desinfecção das mãos; Hospitais; Pesquisa Qualitativa.

ABSTRACT: Aim: to analyze the meanings attributed by the people admitted to a hospital in southern Brazil to messages conveyed by posters in a campaign to promote hands hygiene. Method: qualitative, descriptive and exploratory study. Interviews were conducted with 10 patients. Data were submitted to thematic analysis based on the theoretical references of Cultural Studies. Results: the meanings assigned to the messages varied, which resulted in numerous interpretations. The users represented hand hygiene as an action that is a responsibility of the health professional to prevent the transmission of infections. Conclusion: the meanings assigned to the messages by the patients were different from the ones the campaign producers had expected, resulting on non-compatible answers to their objectives.

Descriptors: Health education; Infection control; Hand disinfection; Hospitals; Qualitative Research.

RESUMEN: Objetivo: analizar los sentidos atribuidos por personas internadas, en un hospital del sur de Brasil, a los mensajes contenidos en los carteles de campaña para la promoción de la higienización de las manos. Método: estudio cualitativo exploratorio y descriptivo. Los datos fueron recolectados por medio de entrevistas con 10 pacientes. Se hizo el análisis temático con base en el referencial de los Estudios Culturales. Resultados: fueron atribuidos sentidos diversos a los mensajes de los carteles, resultando en lecturas y

\footnotetext{
${ }^{1}$ Enfermeira, Mestre em enfermagem, Hospital de Clínicas de Porto Alegre, Porto Alegre, Rio Grande do Sul, Brasil, e-mail:caremlovatto@gmail.com

2 Enfermeira, Doutora em Enfermagem, Universidade Federal da Fronteira Sul, Chapecó, SC, Brasil, email: maira.rossetto@uffs.edu.br

${ }^{3}$ Enfermeira, PhD. em Educação em Saúde, Escola de Enfermagem/UFRGS, Porto Alegre, RS, Brasil, e-mail: dora@enf.ufrgs.br
} 


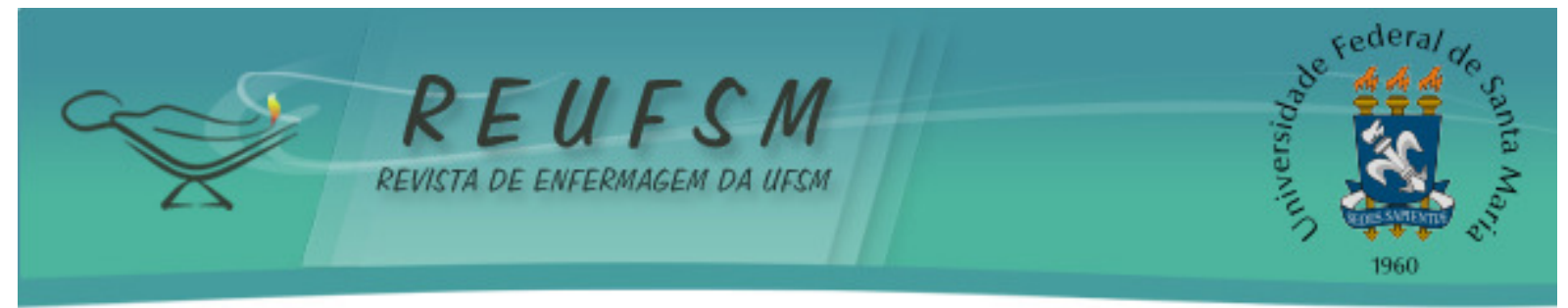

respuestas distintas a la campaña. Como acción, la higienización de las manos fue representada por esos sujetos como una responsabilidad específica del profesional para evitar infecciones. Consideraciones Finales: los sentidos atribuidos a los mensajes por los pacientes fueron diferentes de los esperados por los productores de la campaña, resultando en respuestas no compatibles con sus objetivos.

Descriptores: Educación en Salud; Control de infecciones; Desinfección de las manos; Hospitales; Investigación Cualitativa.

\section{INTRODUÇÃO}

Reconhecida mundialmente como importante na assistência à saúde, a higienização de mãos é a medida mais eficaz e simples para prevenir infecções. ${ }^{1-3}$ As infecções relacionadas à assistência à saúde (IRAS) constituem um problema grave, aumentando tempo de internação, morbidade e mortalidade, resultando em gastos excessivos para o sistema de saúde e sofrimento desnecessário dos usuários. ${ }^{1-3}$

Apesar do seu potencial preventivo para as IRAS, a adesão à higienização de mãos ainda é baixa e sofre influência de múltiplos e complexos fatores, envolvendo aspectos comportamentais, culturais e institucionais. ${ }^{2,4-6}$ Para aumentar a adesão dos profissionais à higienização de mãos recomenda-se o uso de estratégias que combinem educação, motivação e mudança da cultura institucional, valorizando-se esta prática como parte das ações destinadas à segurança do usuário. ${ }^{2,4}$

Nesse sentido, a Comissão de Controle de Infecção Hospitalar de um hospital do sul do Brasil tem investido no aumento da adesão à higiene de mãos na instituição por meio de ações preconizadas pela Organização Mundial de Saúde (OMS) e Agência Nacional de Vigilância Sanitária (ANVISA)..$^{6-7}$ A campanha "Empoderamento dos Pacientes" foi produzida na instituição com esta finalidade, contando com a utilização de cartazes fixados nas enfermarias cujas mensagens estimulavam os usuários internados a uma atitude de protagonismo ao demandarem dos profissionais que higienizassem suas mãos antes de prestarem cuidados. Até então, a viabilidade deste tipo de participação da pessoa internada em programas de estímulo à higienização de mãos dos profissionais ainda era desconhecida. ${ }^{8} 0$ caráter inovador da campanha também se destacava em função de ser esta a primeira vez que a instituição estimulava os usuários ao protagonismo na promoção de um cuidado qualificado pela demanda à prática da higienização de mãos.

A campanha tinha como foco secundário os profissionais, considerando a baixa adesão desses à prática da higienização de mãos na instituição e sua importância como prevenção em momentos que antecedem momentos assistenciais, situações em que essa prática é comumente negligenciada. O caráter educativo da campanha constituía-se a partir do uso de cartazes, cujas mensagens deveriam resultar em escolhas informadas: a informação sobre a importância da higienização de mãos levando os participantes da pesquisa a escolherem agir de acordo. Campanhas de promoção do autocuidado são frequentes, mas o que difere a campanha em tela da maioria é que a ação educativa que ela prevê encoraja o usuário a ter uma atitude vigilante frente a um cuidado que outra pessoa precisa ter com ele.

Outra questão a ser considerada é referente à leitura que os usuários fazem das mensagens dos cartazes e se essas mensagens são realmente eficazes, ou seja, se levam o usuário a agir frente ao profissional de saúde que não higieniza as mãos, de modo a exigir uma mudança de comportamento. Ao longo deste artigo, utilizamos o termo "leitura" partindo da premissa de que ler é mais do que utilizar a capacidade visual: ler também significa dar sentido ao conteúdo dos cartazes, atribuindo significado às figuras e às frases neles contidas. ${ }^{9}$ 


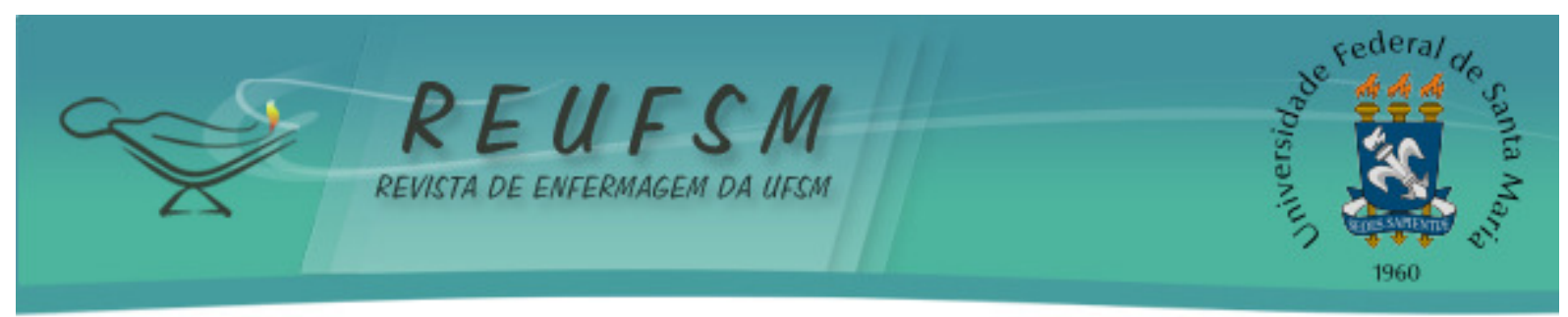

Tal como no cenário da presente pesquisa, a educação em saúde realizada em contextos hospitalares usualmente utiliza como referência para a definição de conteúdos os riscos à saúde já conhecidos e, para a escolha de metodologias educativas, a lógica da responsabilização individual, ênfase que tem sido alvo de críticas. Para intermediar a comunicação entre profissionais e usuários, frequentemente estas ações educativas utilizam-se de materiais educativos impressos. ${ }^{10-11}$ As críticas têm sido, principalmente, relacionadas ao conteúdo das mensagens comunicadas nesses materiais, tradicionalmente originadas na racionalidade biomédica e as estratégias escolhidas para produzir e efetivar a comunicação, as quais são geralmente lineares, unilaterais e de difícil entendimento para os usuários. ${ }^{10-12}$ Como refere a literatura, mensagens de impressos em saúde devem ser claras e objetivas para facilitar o processo comunicativo. ${ }^{11}$ Interpretadas de acordo com os modos de vida dos indivíduos, estas mensagens podem assumir sentidos diversos e, consequentemente, originar formas de pensar e agir diferentes das esperadas pelos produtores dos impressos.

A pesquisa que dá origem ao presente artigo se apoia no referencial teórico dos Estudos Culturais, tendo em conta a análise do conjunto de significados e práticas culturais que circulam na sociedade e apostando no seu potencial para compreender os padrões de comportamento e as ideias compartilhadas no convívio social. ${ }^{9}$

Ao valorizarem os saberes populares, os Estudos Culturais assumem uma perspectiva ampliada de cultura, explorando as práticas culturais. Estas são entendidas como instâncias educativas que constituem os indivíduos por meio de ideias, representações e identidades culturais. ${ }^{9,13}$ Dois conceitos oriundos dos Estudos Culturais são utilizados para a análise: um é referente aos modos de endereçamento e o outro à representação cultural..$^{9,14}$ Os modos de endereçamento têm relação à necessidade de endereçar qualquer comunicação a alguém. Essa perspectiva, utilizada primeiramente pelos teóricos do cinema e ressignificada para a área da educação, argumenta que, ao produzir um cartaz, os produtores idealizam determinados espectadores, a partir de pressupostos conscientes e inconscientes de quem eles são. ${ }^{14} \mathrm{O}$ termo "representação" refere-se ao processo pelo qual os significados são produzidos e veiculados por meio da linguagem. Conforme o referencial dos Estudos Culturais, os significados que resultam de processos de representação reforçam as posições de sujeito. Posições de sujeito são identidades construídas culturalmente e que são ocupadas na medida em que seus significados convidam o indivíduo a assumir essa posição. ${ }^{15}$ Neste sentido, representação é a produção de uma rede de significações instituídas e postas em circulação por meio da linguagem. Pertencer à mesma cultura significa compartilhar um mesmo conjunto de significados. ${ }^{9}$

Considerando esses pressupostos desenvolveu-se uma pesquisa com o objetivo de analisar os sentidos atribuídos por pessoas internadas em um hospital do sul do Brasil às mensagens veiculadas por cartazes em campanha para a promoção da higienização de mãos.

\section{MÉTODO}

O estudo foi desenvolvido por meio de uma abordagem qualitativa, do tipo descritivo-exploratória, utilizando como estratégia metodológica a realização de entrevistas semiestruturadas com usuários internados em uma unidade de doenças infectocontagiosas, de um hospital da Região Sul do Brasil. Esta unidade possui 34 leitos, dois deles privativos e os demais, semiprivativos, cada enfermaria possui uma pia e um dispensador de álcool gel na entrada do quarto, além de um cartaz da campanha, fixado próximo aos pacientes. 


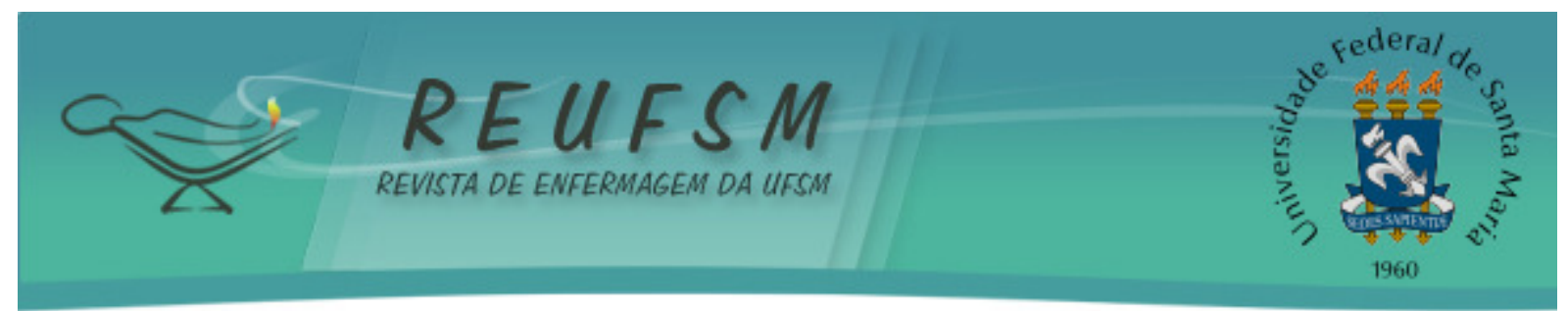

Dez usuários participaram da pesquisa e os critérios de inclusão foram: saber ler e tempo de internação de, no mínimo, cinco dias, sendo o período considerado suficiente para que os usuários tivessem lido as informações contidas nos cartazes e vivenciado situações de cuidado com distintos profissionais, interações importantes para o escopo da pesquisa. Os critérios de exclusão foram: limitação física ou clínica que impedissem a visualização das imagens e leitura das mensagens e a realização de entrevista.

A entrevista foi constituída de perguntas semiabertas. No momento da entrevista a pesquisadora mostrou aos participantes da pesquisa o cartaz fixado na enfermaria na qual estavam internados. Os demais cartazes não foram mostrados aos participantes do estudo. As principais perguntas foram: 0 que mais chama sua atenção neste cartaz? Para quem foi feito este cartaz? 0 que significam as figuras destes cartazes? 0 que as frases destes cartazes querem dizer? As perguntas foram referentes ao entendimento dos usuários sobre higienização de mãos, seu posicionamento frente a ideia de pedir ao profissional para higienizar as mãos e o sentido das mensagens dos cartazes, tanto escritas como das figuras nela contidas.

A coleta de informações ocorreu entre os meses de dezembro de 2011 e janeiro de 2012 e, para análise, foram escolhidos os três cartazes da campanha afixados no ambiente onde os participantes estavam internados. Os seguintes elementos analíticos compunham os cartazes da campanha:

Cartaz 1: Frases - Seu médico está aqui para cuidar e escutar você. Antes do atendimento, pergunte se ele higienizou as mãos. Figura: Uma médica com um estetoscópio.

Cartaz 2: Frases - Você também é responsável pela sua saúde. No hospital, siga o tratamento indicado e ajude seu médico a lembrar de higienizar sempre as mãos. Figura: Uma pessoa segurando uma flor margarida.

Cartaz 3: Frases - Você também é responsável pela sua saúde. No hospital, siga o tratamento indicado e ajude seu médico a lembrar de higienizar sempre as mãos. Figura: A mão de uma pessoa segurando uma rosa.

Seguiu-se o critério de saturação de dados, interrompendo as entrevistas quando a coleta de informações não forneceu novos elementos para a pesquisa. ${ }^{16}$

Os dados foram submetidos à análise temática. ${ }^{17} \mathrm{Na}$ pré-análise foram realizadas as transcrições e leitura exaustiva das entrevistas, seguidas pela organização das informações, utilizando-se como recurso o software $\mathrm{N}$-vivo 7.0. Na fase de exploração do material, foram feitas a classificação e agregação das falas para, posteriormente, categorizar as informações. Nesta fase, buscou-se apreender informações sobre a leitura que os participantes da pesquisa faziam das mensagens comunicadas, comparando-as por semelhanças e diferenças. A etapa final de análise consistiu na interpretação das categorias obtidas, a fim de responder ao objetivo da pesquisa.

0 artigo traz a análise do conteúdo da categoria "A Polissemia da Higienização de Mãos", recortando-se os resultados da dissertação "Sobre o protagonismo de usuários: análise de uma campanha para a adesão à higienização de mãos".

Atendendo a resolução 196/96, o projeto de pesquisa número 110481 foi aprovado pela Comissão de Ética em Pesquisa do Hospital que foi campo do estudo, em 11/10/2011. Cada participante assinou o Termo de Consentimento Livre e Esclarecido, tendo sido informado, previamente, sobre seus objetivos, procedimentos de pesquisa e confidencialidade. No intuito de preservar a identidade dos participantes da pesquisa, nos trechos de entrevista transcritos, foi adotada a denominação "Usuário", seguida de numeração de 1 a 10. 


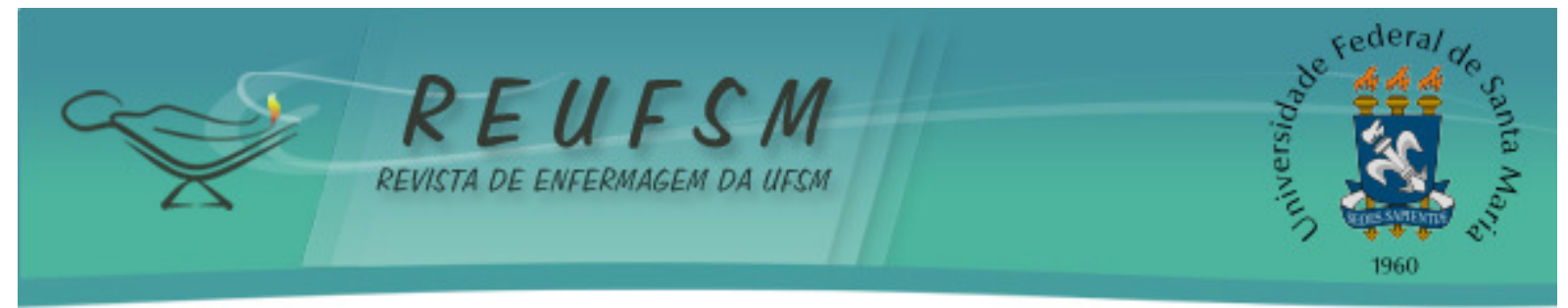

\section{RESULTADOS E DISCUSSÃO}

Da categoria “A Polissemia da Higiene de Mãos”, emergiram duas subcategorias: "Higienizar as mãos - a construção de um sentido", contendo informações referentes à representação da expressão 'higienização de mãos' e "Higienizar as mãos: seu dever e meu também”, contendo representações de higienização de mãos como ação, destacando-se as representações sobre quem deve realizá-la e por que isso deve acontecer.

\section{Higienizar as mãos: a construção de um sentido}

Na campanha "Empoderamento dos Pacientes" a expressão higienização das mãos é utilizada para definir a fricção das mãos com álcool gel ou lavagem das mãos com água e sabonete. Este sentido, esperado pelos produtores da campanha, foi ressaltado por alguns participantes da pesquisa.

Lavar as mãos ou higienizar as mãos é mais ou menos a mesma coisa, ou passa lá [na pia] e lava as mãos, seca na toalha ou só passa [nas mãos] o álcool gel. (Usuário 3)

A análise indica que a compreensão dos usuários sobre o termo "higienização de mãos" passa pelo compartilhamento de uma representação comum a todos, que é a de uma ação que objetiva limpar as mãos. A diferença entre lavar e higienizar estaria mais no tipo de insumo utilizado. De um lado, utilizaria água e sabonete, de outro, álcool gel.

Lavar é lavar com sabão e com água, com bastante água. Higienizar seria com álcool [...]. (Usuário 6)

Higienizar as mãos quer dizer que as mãos têm que estar limpas com o álcool. (Usuário 4)

A diferenciação entre lavar e higienizar pode estar atrelada ao fato de que o uso da expressão "higienização de mãos" é relativamente nova, tanto no cotidiano das pessoas, quanto no ambiente hospitalar. Por muitos anos, a lavagem de mãos com água e sabonete era a única alternativa para prevenir a transmissão de infecção dentro e fora dos serviços de saúde. A introdução do álcool gel nos serviços de saúde partiu de uma iniciativa da OMS que em 2005, lançou o projeto Aliança Mundial para Segurança do Paciente. ${ }^{7}$

Como destaca a literatura, ${ }^{9}$ as mudanças sociolinguísticas podem acontecer com o passar do tempo: várias palavras podem cair em desuso e novas expressões passam a substituí-las para dar o mesmo significado. Nesse sentido, a OMS vem tentando, nos últimos anos, modificar a convenção sociolinguística do que representava "manter as mãos limpas para evitar infecção no contexto hospitalar", e o que se costumava chamar de lavagem de mãos mudou para higienização de mãos. Para que essa convenção sociolinguística seja compartilhada, é necessário que seu sentido seja produzido na prática, pelo trabalho da representação. ${ }^{9}$ As falas a seguir indicam que a convenção sociolinguística do que é higienização de mãos ainda está em construção.

Lavar as mãos é lavar as mãos, é fazer a higiene, e higienizar eu não sei o que é. (Usuário 7) 


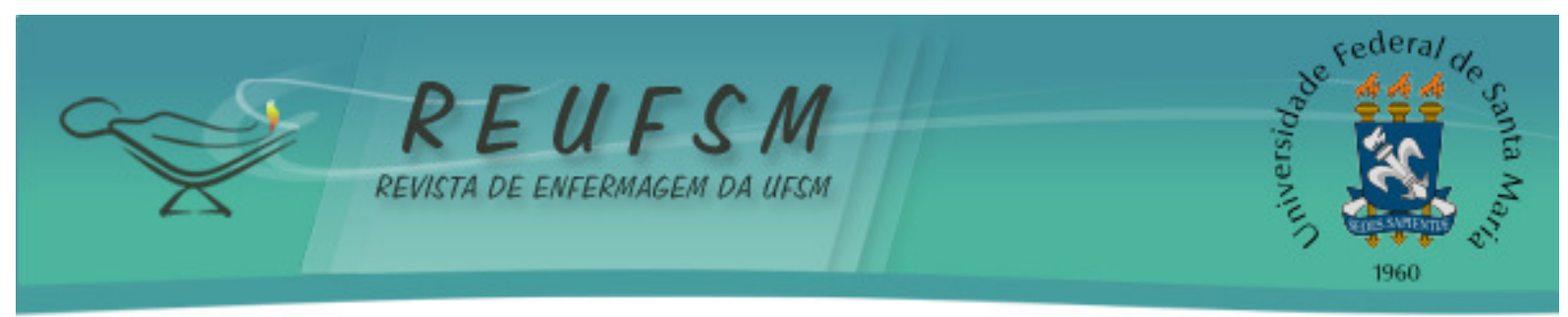

Higienizar as mãos não é a mesma coisa que lavar as mãos, porque daí tem que lavar e passar o álcool nas mãos, se não, não adianta. (Usuário 5)

Eu acho assim, lavar as mãos, acho que é mais do que passar um simples álcool gel na mão. Higienizar é uma coisa mais rápida, talvez uma lavagem de mãos rápida para fazer um procedimento que precisa de uma certa urgência. (Usuário 2)

A análise sugere que a representação produzida por esses usuários para as mensagens da campanha ocorreu, principalmente, por meio da observação das ações de cuidado experimentados durante a internação, em especial dos modos de higienização de mãos observados e da leitura da linguagem não verbal expressa nestas ações. Isso é indicativo de que o hospital é um espaço produtor de significados para o cuidado em saúde e que estes podem ser conflitantes com as mensagens da campanha.

A análise sugere que os modos de endereçamento da campanha podem não acertar seu alvo. Pode-se argumentar, portanto, que não há como esperar uma única resposta a cada modo de endereçamento empregado. ${ }^{14}$

\section{Higienizar as mãos: seu dever e meu também}

Ainda que os modos de endereçamento dos cartazes tenham um sentido preferencial para seus produtores, este será sempre interpretado pela forma como os indivíduos os representam. ${ }^{14} \mathrm{~A}$ conclusão de que não há ajustes perfeitos entre a resposta aos modos de endereçamento idealizados pelos produtores da campanha e a leitura que os usuários fazem dela, não tem a ver apenas com o modo como as representações da palavra higienização influenciaram tal resposta. Também as representações produzidas com relação à ação higienização de mãos foram influentes, destacando-se a compreensão sobre quem deve realizá-la e por que ela deve acontecer. A partir dos modos de endereçamento presentes no cartaz 1, por exemplo, foi produzida a representação da higienização de mãos como uma ação que faz parte do conjunto de responsabilidades dos profissionais.

Eu penso que, se você é médico e está com um aparelho, tem obrigação de se preservar e preservar os outros [falando da higienização de mãos]. (Usuário 9)

O médico está aqui pra cuidar das pessoas. Eu acho que é para os funcionários terem um pouco mais de consciência de fazer [higienizar as mãos] antes de atender as pessoas. (Usuário 4)

Eu vejo uma médica e o estetoscópio, eu acho que é para lembrar alguma coisa, mas eu não sei o que é. Ela parece que quer cuidar das pessoas que estão aqui, deve ser para lembrar isso (Usuário 10)

Não só as palavras ou as imagens, mas os objetos em si podem funcionar como signos no processo de representação. ${ }^{9}$ As falas dos usuários indicam que os modos de endereçamento do cartaz 1 sugerem que é função do médico higienizar as mãos, parecendo estar implícito nesta mensagem a relação entre higienização de mãos, saúde e prática médica. Tais representações estão associadas a três signos presentes no cartaz: o estetoscópio e o jaleco branco, ambos culturalmente representativos do profissional médico, e a frase "seu médico está aqui para cuidar e escutar você". 


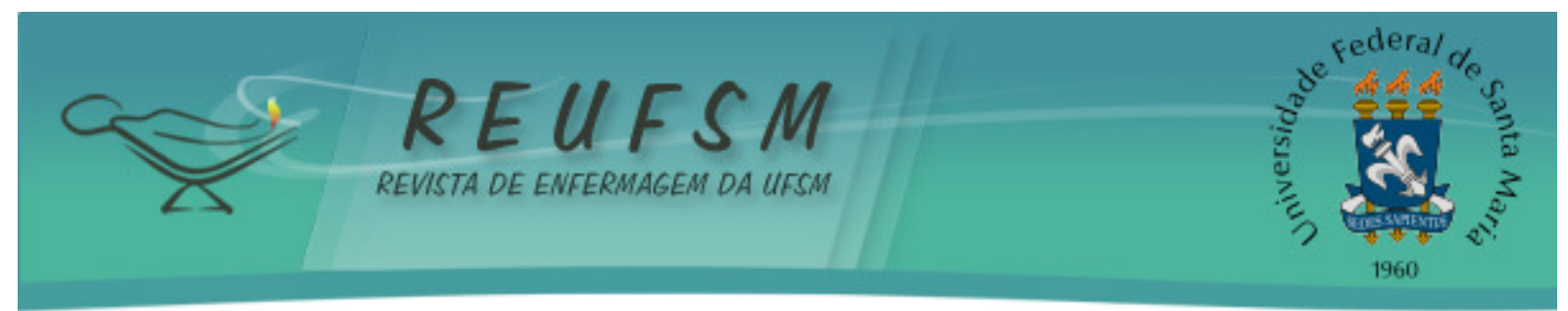

A importância da higienização de mãos antes do cuidado também é destacada pela usuária 4. Embora, seja amplamente enfatizada na literatura a importância da realização de medidas para a segurança do usuário hospitalizado, estudos revelam que a frequência com que os profissionais higienizam as mãos antes do cuidado é menor do que após o cuidado, sugerindo que eles realizam o procedimento mais para evitar se contaminar no contato com o usuário do que para protegê-lo. ${ }^{1-3}$ Tais resultados indicam que a higienização de mãos dos profissionais sofre influência de fatores que não são, necessariamente, relacionados ao conhecimento sobre a importância da adesão a essa prática para a segurança do usuário. Ao representarem a higienização de mãos dos profissionais como um ato responsável, os usuários também indicam porque essa prática deve ser realizada. Os modos de endereçamento dos cartazes 2 e 3 forneceram elementos para a produção desta representação.

[0 cartaz] "ensina a lavar as mãos. [...] Que todos [os profissionais] tem que deixar as mãos higienizadas, limpas e com cheiro agradável” [representando a margarida] (Usuário 7)

\section{A rosa tem que ficar bonita depois de lavar as mãos. (Usuário 1)}

Uma das representações da higienização de mãos sugerida nessas falas tem relação com a percepção de que essa prática resultaria em aspecto e aroma compatíveis com limpeza. Essa associação entre perfume, limpeza e ausência de germes é bastante comum no cotidiano de todos nós, consumidores de produtos vendidos com base justamente nessa lógica. A representação da higienização de mãos como algo que resulta no "belo, limpo e com aroma agradável” também aparece, e de modo explícito, nos cartazes, nas figuras de flores.

Os dados indicam que os participantes da pesquisa compreenderam que a campanha "Empoderamento dos Pacientes" tem como objetivo conscientizar ou ensinar os membros da equipe de saúde sobre a importância da higienização de mãos. No caso específico do hospital em tela, onde a higienização de mãos faz parte do cotidiano das ações em saúde, é justificável que essas representações, produzidas no contexto da campanha, sejam coerentes com o que é enfatizado pela OMS sobre a importância desse procedimento para a segurança dos usuários. ${ }^{7}$

A higienização de mãos como uma ação do profissional que se preocupa com a prevenção de infecções é outra representação destacada pelos entrevistados, indicando que o objetivo final dessa ação deve resultar em um cuidado seguro.

Higienizar as mãos é fundamental, por isso que a pia está ali e eles [os profissionais] fazem isso porque é uma maneira de controlar as bactérias para não contaminar outros pacientes. (Usuário 9)

Eu acho que é pra não pegar o que eu tenho e pra não passar para as outras pessoas. (Usuário 1)

As falas indicam que os usuários têm conhecimento sobre os riscos de adquirirem uma infecção hospitalar quando essa é negligenciada pelos profissionais no cotidiano dos cuidados em saúde. Tal representação parece ter sido construída por meio da linguagem não verbal dos profissionais, quando esses foram observados higienizando as mãos, mas pode também terem sido produzidas por meio de outras experiências dentro ou fora do hospital. O conhecimento sobre a importância da limpeza das mãos circula no meio social e 


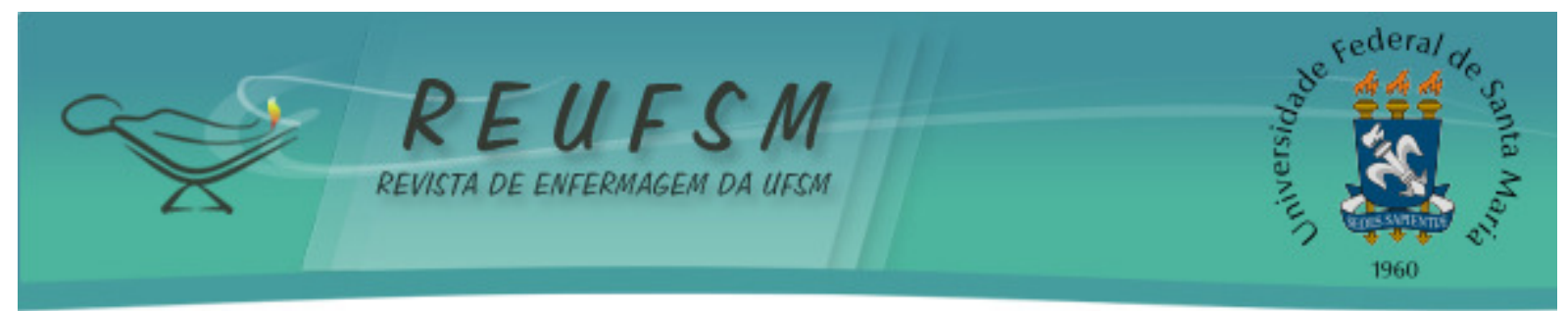

independe de uma ação educativa formal. Muito longe de ser uma "caixa vazia"18, o usuário já chega ao hospital com informações e percepções sobre a importância da higienização de mãos.

Outra representação produzida a partir dos modos de endereçamento dos cartazes da campanha tem a ver com a higienização de mãos como ação de autocuidado. A análise das entrevistas sugere que a frase que aparece nos cartazes 1 e 3, "Você também é responsável pela sua saúde", contribuiu para tal representação.

Eu acho que este cartaz quer dizer que é pra cuidar melhor da saúde, né? (Usuário 1)

Que a gente tem que ajudar a cuidar de si mesmo. (Usuário 8)

No campo da saúde, os discursos em torno da imperiosa necessidade de autocuidado são bastante usuais, responsabilizando-se 0 indivíduo pela adesão a comportamentos saudáveis. A representação de autocuidado que os produtores da campanha pretendem transmitir, contudo, tem outro sentido. Na campanha, autocuidado é referente à ação de um indivíduo - o usuário - a ser realizada com o objetivo de modificar o comportamento de outro; nesse caso, do profissional. Essa nova representação para o autocuidado pode ser de difícil leitura e interpretação, uma vez que os indivíduos a serem "educados" estão acostumados a ações educativas que visam o cuidado de si, sem que essa ação impacte no comportamento de outros.

Considera-se como limitação do estudo, o mesmo ter sido realizado em uma unidade de doenças infectocontagiosas, onde a prevenção da transmissão de infecção é enfatizada, o que pode ter influenciado as respostas dos entrevistados.

\section{CONCLUSÃO}

Conclui-se que a expressão "higienização de mãos" é polissêmica, assumindo sentidos nem sempre convergentes com a definição preconizada pela campanha, e que essa polissemia repercute no modo não uniforme como os usuários leem e respondem às mensagens. Como ação, a higienização das mãos é representada pelos participantes do estudo como uma responsabilidade do profissional para manter as mãos limpas e evitar a transmissão de infecção.

Outro aspecto importante a destacar a partir da análise é a produção de diversas representações para a higienização de mãos, como expressão e ação. Essas representações não estão, necessariamente, condicionadas aos modos de endereçamento dos cartazes, sofrendo também influência de fatores externos à campanha, como, por exemplo, dos saberes sobre autocuidado aprendidos no cotidiano e da observação do comportamento dos profissionais durante a internação.

A análise reforça o argumento, defendido nas abordagens críticas sobre o tema da educação em saúde, de que, na maioria das vezes, as ações educativas reconhecem o usuário como um leigo em saúde, o que reduz as possibilidades de uma educação pautada no diálogo e no compartilhamento de saberes.

Embora a falta de estudos sobre campanhas educativas em contextos hospitalares tenha dificultado a interlocução com outros achados de pesquisa, este estudo trouxe importantes subsídios para este campo de conhecimento, contribuindo com a análise de ações educativas que visem ao protagonismo do usuário em ações de autocuidado no ambiente hospitalar. Do mesmo modo, esta pesquisa contribui para o estudo de ações educativas mediadas por impressos, colocando em pauta seus limites e possibilidades. No contexto hospitalar, existem limites para a produção do protagonismo dos usuários a partir 


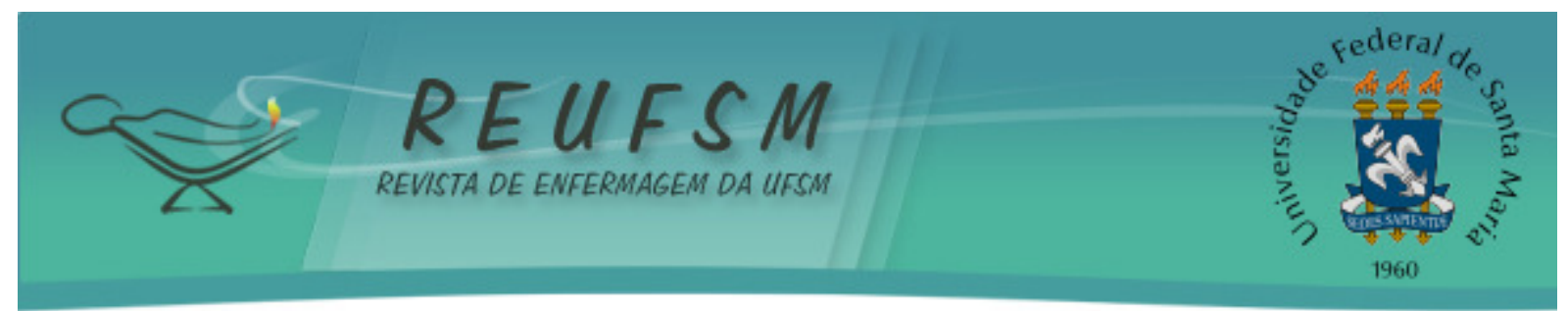

de campanhas educativas. As mensagens que se pretende transmitir podem receber diferentes leituras, dependendo de quem as lê e isto poderá interferir no modo como os usuários respondem a estas. Além disto, é importante destacar que o protagonismo pretendido pela campanha em questão deveria ter se constituído desde o seu início, incentivando o envolvimento dos usuários na sua produção e avaliação.

A enfermagem ocupa um espaço importante no campo da educação em saúde e na produção de impressos informativos/educativos no contexto hospitalar, embora sejam escassos os estudos de enfermeiros que analisem os resultados dessas ações, em especial na perspectiva dos Estudos Culturais. Neste sentido, a pesquisa contribui para a reflexão e a crítica sobre o emprego deste tipo de ação educativa pela enfermagem.

Sugere-se que novas pesquisas sejam desenvolvidas de modo a ampliar a compreensão sobre os sentidos atribuídos pelos usuários às mensagens comunicadas em ações educativas intermediadas por impressos que ocorrem no cenário hospitalar, e sobre sua influência nas mudanças de comportamento esperadas.

\section{REFERÊNCIAS}

1. Kapil R, Bhavsar HK, Madan M. Hand hygiene in reducing transient flora on the hands of healthcare workers: an educational intervention. Indian J Med Microbiol. 2015;33(1):125-8.

2. Midturi JK, Narasimhan A, Barnett T, Sodek J, Schreier W, Barnett J, et al . A successful multifaceted strategy to improve hand hygiene compliance rates. Am J Infect Control. 2015;43(5):533-6.

3. Lhakhang P, Lippke S, Knoll N, Schwarzer R. Evaluating Brief Motivational and SelfRegulatory Hand Hygiene Interventions: A Cross-over Longitudinal Design. BMC Public Health [Internet]. 2015 [acesso em 2016 mar 28];15(79):[9 pages]. Disponível em: http://www.ncbi.nlm.nih.gov/pmc/articles/PMC4323073/.

4. Smiddy MP, O' Connell R, Creedon SA. Systematic qualitative literature review of health care workers' compliance with hand hygiene guidelines. Am J Infect Control. 2015;43(3):269-74.

5. Walker JL, Sistrunk WW, Higginbotham MA, Burks K, Halford L, Goddard L, et al. Hospital hand hygiene compliance improves with increased monitoring and immediate feedback. Am J Infect Control. 2014;42(10):1074-8.

6. Prado MF, Hartmann TPS, Teixeira FLA. Acessibilidade da estrutura física hospitalar para a prática da higienização das mãos. Esc Anna Nery Rev Enferm.2013;17(2):220-6.

7. Santos TCR, Roseira CE, Piai-Morais TH, Figueiredo RM. Higienização das mãos em ambiente hospitalar: uso de indicadores de conformidade. Rev Gaúcha Enferm. 2014 mar;35(1):70-7.

8. Kim MK, Nam EY, Na SH, Shin M, Lee HS, Kim NH, et al. Discrepancy in perceptions regarding patient participation in hand hygiene between patients and health care workers. Am J Infect Control. 2015;43(5):510-5.

9. Hall S. Representation: cultural representations and signifying practices. London/Thousand Oaks/New Delhi: Sage/Open University; 1997.

10. Gozzo TO, Lopes RR, Prado MAS, Cruz LAP, Almeida AM. Informações para a elaboração de um manual educativo destinado às mulheres com câncer de mama. Esc Anna Nery Rev Enferm. 2012;16(2):306-11. 


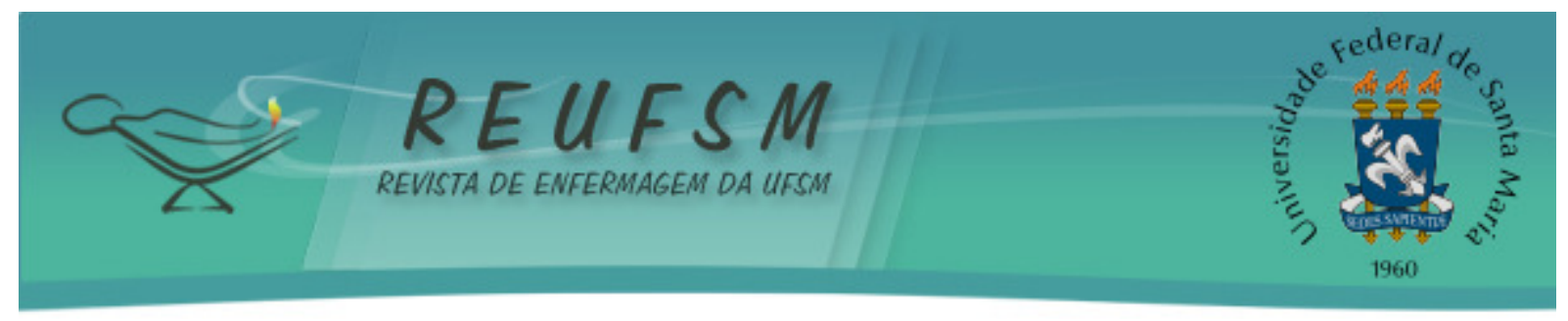

11. Lopes JL, Nogueira-Martins LA, Barbosa DA, Barros ALBL. Construção e validação de um manual informativo sobre o banho no leito. Acta Paul Enferm.2013;26(6):554-60.

12. Protheroe J, Estacio EV, Saidy-Khan S. Patient information materials in general practices and promotion of health literacy: an observational study of their effectiveness. Br J Gen Pract. 2015;65(632):192-7.

13. Dias AF. Dos estudos culturais ao novo conceito de identidade. Rev Fórum Identidades. 2011;9(9):151-66.

14. Ellsworth E. Modo de endereçamento: uma coisa de cinema; uma coisa de educação também. In: Silva TT, organizador. Nunca fomos humanos: nos rastros do sujeito. Belo Horizonte (MG): Autêntica ; 2001. p: 21-53.

15. Paraíso MA, Reis CA. Normas de gênero em um currículo escolar: a produção dicotômica de corpos e posições de sujeito meninos-alunos. Estud Fem. 2014;22(1):237-56.

16. Fontanella BJB, Luchesi BM, SMGB, Ricas J, Turato ER, Melo DG. Amostragem em pesquisas qualitativas: proposta de procedimentos para constatar saturação teórica. Cad Saúde Pública. 2011 fev;27(2):389-94.

17. Minayo MCS. O desafio do conhecimento: pesquisa qualitativa em saúde. $12^{\mathrm{a}}$ ed. São Paulo (SP): Hucitec; 2014.

18. Freire P. Pedagogia da autonomia: saberes necessários à prática educativa. São Paulo (SP): Paz e Terra; 1996.

Data de recebimento: 25/02/2016

Data de aceite:16/09/2016

Contato do autor responsável: Carem Gorniak Lovatto

Endereço postal: Rua Ramiro Barcelos, 2350. Comissão de Controle de Infecção

Cep:90035-903 - Porto Alegre, RS

e-mail: caremlovatto@gmail.com 